\title{
Spitzer Reassesses His 2003 Study of Reparative Therapy of Homosexuality
}

\author{
Robert L. Spitzer
}

Published online: 24 May 2012

(c) Springer Science+Business Media, LLC 2012

Several months ago, I told the Editor of Archives of Behavior that, because of my revised view of my study of reparative therapy changing sexual orientation (Spitzer, 2003a), ${ }^{1}$ I was considering writing something that would acknowledge that I now judged the major critiques of the study as largely correct. After discussing my revised view of the study with Gabriel Arana (see Arana, 2012), a reporter for The American Prospect, and with Malcolm Ritter, an Associated Press science writer, I decided that I had to make public my current thinking about the study. Here it is.

\section{Basic Research Question}

From the beginning, it was: Can some version of reparative therapy enable individuals to change their sexual orientation from homosexual to heterosexual? Realizing that the study design made it impossible to answer this question, I suggested that the study could be viewed as answering the question: How do individuals undergoing reparative therapy describe changes in sexual orientation? A not very interesting question.

\section{The Fatal Flaw in the Study: There Was No Way to Judge the Credibility of Subject Reports of Change in Sexual Orientation}

I offered several (unconvincing) reasons why it was reasonable to assume that the participants' reports of change were credible

This letter refers to the article available at doi: 10.1023/A:1025647527010.

R. L. Spitzer $(\bowtie)$

7 Random Road, Princeton, NJ 08540, USA

e-mail: spitzer8@verizon.net and not self-deception or outright lying. But the simple fact is that there was no way to determine if the participants' accounts of change were valid.

I believe I owe the gay community an apology for my study making unproven claims of the efficacy of reparative therapy. I also apologize to any gay person who wasted time and energy undergoing some form of reparative therapy because they believed that I had proven that reparative therapy works with some "highly motivated" individuals.

\section{References}

Arana, G. (2012, April 11). My so-called ex-gay life. The American Prospect. Retrieved from http://prospect.org/article/my-so-calledex-gay-life.

Drescher, J., \& Zucker, K. J. (Eds.). (2006). Ex-gay research: Analyzing the Spitzer study and its relation to science, religion, politics, and culture. New York: Harrington Park Press.

Spitzer, R. L. (2003a). Can some gay men and lesbians change their sexual orientation? 200 participants reporting a change from homosexual to heterosexual orientation. Archives of Sexual Behavior, 32, 403-417.

Spitzer, R. L. (2003b). Reply: Study results should not be dismissed and justify further research on the efficacy of sexual reorientation therapy. Archives of Sexual Behavior, 32, 469-472.

Zucker, K. J. (2003). The politics and science of "reparative therapy" [Editorial]. Archives of Sexual Behavior, 32, 399-402.

\footnotetext{
${ }^{1}$ Editor's note. The Spitzer study was published as a "target article" with the understanding that it would be followed by a series of peer commentaries, followed by a reply by Spitzer (2003b). There were 26 commentaries published in the same issue (Zucker, 2003). Subsequent to the publication of the target article, the peer commentaries, and Spitzer's reply, they were reproduced in an edited volume by Drescher and Zucker (2006), which contained an additional five commentaries and an interview with Spitzer by Drescher.
} 